\title{
Streaming Science \#1: An Introduction to Using Mobile Technologies for Engagement with Your Target Audience $^{1}$
}

\author{
Peyton Beattie and Jamie Loizzo ${ }^{2}$
}

\section{Introduction}

This is the first publication in the Streaming Science EDIS series focused on how to use mobile hardware and software for engagement with your target audience. Technology is continuously becoming more advantageous as a tool to connect and interact with diverse groups (Perrin \& Kumar, 2021; Schwab, 2007). Now more than ever, mobile technologies are an integral part of everyday life for most Americans. Research shows $97 \%$ of Americans own a mobile phone, $75 \%$ own a computer, and $50 \%$ own a tablet (Pew Research Center, 2021). Fifteen percent depend on their mobile phone as their sole way to access the internet (Pew Research Center, 2021). Mobile technologies have become advantageous because of their accessibility and cost-effectiveness (Reed, 2016). They have become a game-changer for many industries to more easily connect with their audiences. For instance, the healthcare industry has capitalized on mobile technologies to connect with patients during COVID-19 while maintaining a healthy and safe environment (Healthcare Resource Hub, 2020; Morcos, 2020).

Educational learning environments for youth and adults alike have witnessed a beneficial increase in mobile technology usage. Pre-COVID-19 pandemic, teachers had already begun to utilize instructional technologies for youth engagement as school resources decreased and logistical planning became more difficult to facilitate in-person educational learning experiences outside the classroom (Cassady et al., 2008; Greene et al., 2014). Since the onset of the pandemic, youth use instructional technologies to meet basic, daily learning needs (Reimers et al., 2020). Adults use technology to engage in learning experiences and as a resource to explore their curiosities about scientific issues (Hague, 2009; Lederman, 2018). As such, the need for quality communication and educational content for all ages developed and delivered via mobile technologies is evident. This article and series of publications emphasize the creation of communication and educational content via mobile technologies. The information can be useful for communicators and educators in a variety of settings (i.e., formal or nonformal) and guide the development of digital engagement experiences for youth and adult audiences.

\section{Streaming Science}

Dr. Jamie Loizzo originally created Streaming Science at the University of Nebraska-Lincoln in 2016, and she continues to facilitate the platform with a team of colleagues and graduate students at the University of Florida in the Department of Agricultural Education and Communication. The Streaming Science project was created as way for agricultural communication students to develop their

1. This publication is AEC736, one of a series of the Department of Agricultural Education and Communication, UF/IFAS Extension. Original publication date October 2021. Visit the EDIS website at https://edis.ifas.ufl.edu for the currently supported version of this publication.

2. Peyton Beattie, Extension agent I, community resource development, UF/IFAS Extension Clay County; and Jamie Loizzo, assistant professor and e-learning coordinator, Department of Agricultural Education and Communication; UF/IFAS Extension, Gainesville, FL 32611.

The Institute of Food and Agricultural Sciences (IFAS) is an Equal Opportunity Institution authorized to provide research, educational information and other services

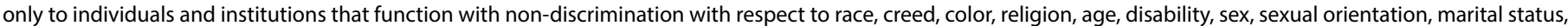

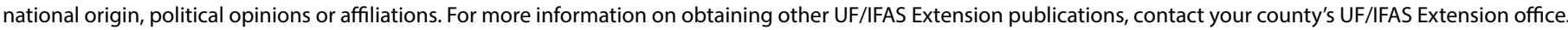
U.S. Department of Agriculture, UF/IFAS Extension Service, University of Florida, IFAS, Florida A \& M University Cooperative Extension Program, and Boards of County Commissioners Cooperating. Nick T. Place, dean for UF/IFAS Extension. 
21st-century multimedia skills through the development and dissemination of online communication products for public audiences. Students within Loizzo's project-based learning courses produce photo essays, videos, podcasts, virtual reality tours, electronic field trips, and more for the Streaming Science platform. The project's website can be accessed at www.streamingscience.com. The student work featured on the Streaming Science website is also shared on Facebook (@StreamingScience), YouTube (@StreamingScience), Twitter (@Streaming_Sci), and Instagram (@StudentsStreamingScience). Lessons learned and guidance from the Streaming Science project are shared in this publication series for you to replicate the mobile technology usage and approaches for creating your own content for youth and adult audiences within your varying contexts. If you do not have an existing online science communication and education outlet, you are encouraged to contact Streaming Science about a potential partnership for distribution.

\section{Mobile Technologies}

Mobile technology provides a long list of advantageous conveniences. For example, a large majority of people have access to some type of mobile device (Pew Research Center, 2021); the technology is easy to transport and generally more readily available than a desktop computer, professional digital single lens reflex (DSLR) camera, or high-end video camera (IBM, n.d.); and mobile devices often cost less than professional-grade communications hardware (Reed, 2016).

Formal and nonformal educators alike can easily integrate mobile technologies into their educational environments via cell phones or other mobile devices. Formal educators can use mobile technologies to connect with content experts outside the classroom to give students a more immersive experience with those experts who are at a distance. Formal educators have the opportunity to organize these experiences on their own or connect with entities that are already organizing these types of experiences. Nonformal educators also have an opportunity to engage their youth and adult audiences through mobile technologies in a variety of ways. Most commonly, mobile technologies can be used while immersed in the learning environment.

Streaming Science contributors have used the following mobile technologies to create educational content for audiences of all ages in a variety of settings:

- iPads

- mobile phones (i.e., iPhones, Android phones, etc.)
- MiFi, a mobile wireless internet device

- 360-degree cameras

- laptop computers

The following publications in this EDIS series will discuss how you can use each of these mobile technologies to develop communication products and educational content for your area of expertise and programs. (See Appendix A for a list of the articles in the series.) The publications include recommendations for needed mobile hardware, software, and implementation approaches for the development of:

- Electronic field trips (EFTs) in a one-site-to-many-sites webcast format

- EFTs in the Scientist Online one-on-one dialogue approach

- Podcasts

- $360^{\circ}$ photo-based virtual reality tours

- An online community of practice

- Assessments that measure the impacts of using mobile technologies

\section{Summary}

This first publication in the Streaming Science series is centered around explaining Streaming Science, describing mobile technologies, and setting the stage for the topics of the subsequent publications that focus on the application of mobile technologies for educational content development. This article published in the Agricultural Education Magazine (Volume 92, Issue 1, pages 5-7) focuses on the concept of Streaming Science and would serve as a useful supplemental resource in reference to this publication.

\section{References}

Cassady, J. C., Kozlowski, A. G., \& Kommann, M. A. (2008). Electronic field trips as interactive learning events: Promoting student learning at a distance. Journal of Interactive Learning Research, 19(3), 439-454. https://www. learntechlib.org/primary/p/24187/

Greene, J. P., Kisida, B., \& Bowen, D. H. (2014).

The educational value of field trips. Education Next, 14(1), 79-86. https://www.educationnext.org/ the-educational-value-of-field-trips/

Hague, C. (2009). A review of the current landscape of adult informal learning using digital technologies. Futurelab. https://www.nfer.ac.uk/media/1786/futl23.pdf 
Healthcare Resource Hub. (2020). 6 ways mobile technology is impacting healthcare. Ring-

Central. https://www.ringcentral.co.uk/gb/en/

blog/6-ways-mobile-technology-is-impacting-healthcare/

IBM. (n.d.). Mobile technology. https://www.ibm.com/ topics/mobile-technology

Lederman, D. (2018). Online education ascends. Insider Higher Ed. https://www.insidehighered.com/digitallearning/article/2018/11/07/new-data-onlineenrollmentsgrow-and-share-overall-enrollment

Morcos, R. (2020). How telehealth and mobile devices work hand in hand to increase health outcomes. Forbes. https:// www.forbes.com/sites/forbestechcouncil/2020/09/10/ how-telehealth-and-mobile-devices-work-hand-in-handto-increase-health-outcomes

Perrin, A., \& Kumar, M. (2021). About three-in-ten U.S. adults say they are 'almost constantly' online. Pew Research Center. https://www.pewresearch.org/fact-tank/2021/03/26/ about-three-in-ten-u-s-adults-say-they-are-almostconstantly-online/

Pew Research Center. (2021). Mobile fact sheet. https:// www.pewresearch.org/internet/fact-sheet/mobile/

Reed, A. (2016). How mobile technology lowers cost and increases productivity. Motus. https://www.motus.com/ how-mobile-technology-lowers-costs-and-increasesproductivity/

Reimers, F. M., Schleicher, A., Saavedra, J., \& Tuominen, S. (2020). Supporting the continuation of teaching and learning during the COVID-19 pandemic. https://www.oecd.org/ education/Supporting-the-continuation-of-teaching-andlearning-during-the-COVID-19-pandemic.pdf

Schwab, K. (2007). The fourth industrial revolution. Crown Business.

\section{Appendix A: Streaming Science Series Overview}

Streaming Science \#1: An Introduction to Using Mobile Technologies for Engagement with Your Target Audience Introduces the Streaming Science platform, the mobile technologies students have used to contribute work to the Streaming Science platform, and an overview of types of content created for Streaming Science using mobile technologies.
Streaming Science \#2: Using Webcast Electronic Field Trips for Engagement with your Target Audience Describes the webcast electronic field trip (EFT), how Streaming Science has used the webcast EFT format, and considerations for using this type of instructional and communication technology.

Streaming Science \#3: Using Scientist Online Electronic Field Trips for Engagement with Your Target Audience

Describes the Scientist Online EFT, how Streaming Science has used the Scientist Online EFT format, and considerations for using this type of instructional and communication technology.

Streaming Science \#4: Using Podcasts for Engagement with Your Target Audience

Describes podcasting, how Streaming Science has used podcasting, and considerations for using this type of instructional and communication technology.

Streaming Science \#5: Using Virtual Reality Tours for Engagement with Your Target Audience

Describes virtual reality, how Streaming Science has used virtual reality, and considerations for using this type of instructional and communication technology.

Streaming Science \#6: Using Google Classroom for Engagement with Your Target Audience

Describes Google Classroom, how Streaming Science has used Google Classroom to host an online community of practice, and considerations for using this type of instructional and communication technology.

Streaming Science \#7: Using Evaluation to Assess Engagement with Your Target Audience via Mobile Technologies Describes how Streaming Science has used evaluation measures to determine engagement with target audiences through mobile technologies. 